\title{
National Characteristics and Art Composition Characteristics of Tujia Brocade Art
}

\author{
Ming Hong \\ Wuhan College, Wuhan City, Hubei, 430000, China
}

\begin{abstract}
As one of China's national minorities, Tujia nationality has exerted an important role in the development course of modern national culture. In the development course of national culture of Tujia nationality, its brocade art inherited generation by generation has been extensively applied in art inheritance in modern society. It has also been applied in practical teaching to manifest the unique style and special artistic expression of Tujia brocade art. Under such a context, it is necessary to strengthen analysis on its national characteristics in the art development course and art composition characteristics. For this purpose, this paper makes special analysis on the national characteristics and art composition of Tujia brocade art in the sequence of analysis on the basic components of Tujia brocade art, analysis on its national characteristics and then detailed analysis on its composition characteristics. The author hopes to help people to understand the unique characteristics and results of Tujia brocade art after the analysis in this paper.
\end{abstract}

Keywords: Tujia nationality; Brocade Art; National Characteristics; Art Composition; Characteristics

DOI: http : //dx.doi.org/10.26549/jetm.v2i1.688

$\mathrm{I}$

ntroduction: Amidst the development and inheritance of China's minority culture, Tujia brocade art, as an important inheritance form in the development of minority culture, holds an important in both the development and inheritance of modern minority culture. It is believed that Tujia brocade art has arisen to be the symbol of Tujia people in modern time. Further, the development trend of this art has also kept changing and the progress of its artistic characteristics is employed in teaching work and arrangement, which effectively facilitates the rapid development of Tujia brocade art. Therefore, this paper analyzes the national characteristics and art composition characteristics of Tujia brocade art and is of great research importance for inheritance of Tujia national culture. In addition, the study in this paper can also help people better understand the basic information of Tujia brocade techniques and Tujia brocade art.

\section{Analysis on Basic Components of Tujia Bro- cade Art}

\subsection{Pattern Ornament of Tujia Brocade}

In the development course of Tujia nationality brocade art, a relatively perfect development pattern has been developed. Capturing of the aesthetic elements in life and then further processing of these elements in the design process of brocade patterns make the artistic development of Tujia brocade come true. The pattern ornaments of Tujia brocade incorporate metaphors of Tujia nationality people to their art works and regard metaphor as special bailment to apply it in the handling of realistic works. Through processing of the line structure of patterns in works, flowers, grass and tree in real life as well as birds and animals are presented in patterns ${ }^{[1]}$. 


\subsection{Color Expression of Tujia Brocade}

In the development course, Tujia brocade has placed great emphasis on color processing of brocade works. As a result, bright colors are employed for color processing in analysis and processing of actual works. Bright colors in brocade works not only demonstrate Tujia people's longing for and pursuit of life but also imply their expectation and blessing for life. In addition, in the color processing of brocade works, Tujia people also apply green and environment-friendly elements in the color presentation, echoing with the green development trend of modern brocade works and also meet the color application demands of modern brocade works.

\section{Analysis on National Characteristics of Tujia Brocade Art}

\subsection{Diversified Forms}

As an important symbol of spirit as the Tujia nationality moves forwards, Tujia brocade art has played an important inheritance role in art inheritance and development of modern culture. The national progress of Tujia brocade art is accompanied with the gradual formation of a relatively active inheritance system and also sees the effective diversified development of Tujia brocade art in the application process of this inheritance system. In the development course of Tujia brocade art, Tujia people like to embroid animals, flowers, grass and trees on cotton. ${ }^{[2]}$ Further, in actual design, speical transition analysis has been made in the actual design process, ensuring diversified development of brocade art. For instance, to show Tujia brocade art, Tujia people like to decorate the cotton clothes by animals and plants, make a special theme for each piece of cloth, and then decorate it based on the theme and in the end a piece of artistic works on cotton cloth comes into being. In addition, as such artistic works proceeds, the inherited themes have also kept changing and thus its forms of art also change accordingly, thus contributing to the diversified national characteristics. ${ }^{[3]}$

\subsection{Bright and Vivid Color}

Color represents one of the most important forms to express artistic charm. Tujia brocade art has also attached great importance to color application in its development and application course, effectively ensuring national development of its Tujia brocade art. In color processing of cotton clothes, Tujia people like to decorate the clothes by various colors and choose some bright colors in decoration, such as blue, yellow and red. Color processing of the cotton clothes and special treatment coupled with the brocade art contribute to a new kind of national art style. In other words, bright colors provide a sound development and research direction for brocade art lovers and the application of such a technique has always kept with the progress of Tujia brocade art. ${ }^{[4]}$

\subsection{Ideographic Patterns}

Pattern processing is of significant study importance for brocade art. Tujia brocade art has also placed much emphasis on pattern construction and management of brocade in its development course. Invariable combination of patterns in brocade art with a certain ideographic form and special analysis in the combination process guarantee that the application of each pattern is integrated with its special theme. In addition to ensuring the art inheritance of Tujia brocade, this also provides mystical color for its national development. As a member of China's ethnic minorities, Tujia has developed its own important ethnic belief in the its development course. As a result, Tujia people can integrate the faith elements of brocade art with brocade techniques in brocade treatment. The combination of the two contribute to artistic works with national features.

\subsection{Symmetrical Design}

Given symmetry acts as an important aesthetics exhibition means in brocade art application, Tujia brocade art has also put much stress on symmetry construction and management of brocade in its development and inheritance course and as a result, the aesthetic symmetrical effect is ensured through symmetry construction. In the symmetry construction and research of brocade works, Tujia people like to construct aesthetic elements by decorating the pattern by colors and effectively realizes the integral development of brocade art works in the construction of of symmetrical aesthetics factors. Therefore, among art inheritance and development in the modern society, Tujia people have attached great importance to symmetrical processing of inherited Tujia art works. As a result, in addition to real national development of Tujia brocade art, some elements with national culture features are applied in the symmetrical construction of brocade works and the aesthetic visual effect is ensured. ${ }^{[5]}$

\section{Analysis on Composition Characteristics of Tujia Brocade Art}

\subsection{Unique Art Composition}

As Tujia brocade art is inherited and proceeds, a relatively conspicuous art inheritance characteristics have been developed and kept ongoing and transforming. After nearly one thousand years of development, the composition characteristics of Tujia brocade art are also presented in different aspects gradually. First, as the Tujia brocade art progresses, a unique art composition has been developed, for the artistic expression is always analyzed by an abstract form in its development course. In addition, a relatively perfect artistic structure has been developed in the construction and analysis of its art inheritance forms. According to the development forms of Tujia brocade art, its basic artistic form has been dominated by "planer structure" in modern times and further such a 
unique art structure has also constantly exerted influence on the development of Tujia brocade art.

\subsection{Artistic Patterns and Structures}

Sound pattern processing is necessary in brocade art processing and pattern treatment also represents a kind of aesthetic processing with national characteristics in Tujia brocade art. Among the art composition of Tujia brocade art, the abstract art form by horizontal and vertical lines is applied as the pattern structure. In addition, its basic pattern structure is defined in such an art inheritance form and then pattern design and processing is done based on the existing art inheritance structure. The pattern processing is finished through pattern line process, analysis on pattern's tetragonal structure and special alternate structure processing based on pattern development in sequence. In such a process, stress should be put on pattern's alternate structure processing and plane-to-line intersection position processing of patterns so as to timely well process the artistic structure of brocade works. ${ }^{[6]}$

\subsection{Application of Artistic Elements}

The application of artistic elements in Tujia brocade art also represents an important art structure. In the development of modern brocade art, amidst the constant application of artistic elements in Tujia brocade art, art works are effectively combined with brocade art through the description of mountains and rivers in art works. As a result, in such a combination process, featured development of Tujia brocade art is realized in an effective manner. For instance, in the development course of Tujia brocade art, art works and brocade works are combined through description and construction of lines, such as the description of ecology and nature and presentation and analysis on flowers, grass and trees. All of these lay a good foundation for the development of Tujia brocade art and in the process of brocade art development, artistic elements have been kept constructed and applied. ${ }^{[7]}$

\subsection{Selection of Traditional Culture Connotation}

As the Tujia brocade art progresses, high stress has been put on the construction of traditional cultural elements and its cultural inheritance and development is integrated with modern cultural development. A kind of plain artistic and cultural inheritance form is adopted in the development course of Tujia brocade, integrating the overall brocade art and the development of traditional culture. After nearly one hundred years of development, a trend integrating development of Tujia brocade art and traditional culture development has arosen and the application of its brocade techniques is also seen constant integration with traditional culture. The art inheritance and integration with traditional culture effectively contributes to the sound art composition characteristics of Tujia brocade art. In addition, it makes Tujia brocade art keep up-to-date in the modern society and such a status will linger on as the Tujia brocade art develops and exists. ${ }^{[8]}$

\section{Conclusion}

To sum up, as Tujia brocade acts as a traditional folk culture and art, the cultural inheritance and development connotation of it in its development and inheritance in the modern society should be well mastered and national development of Tujia brocade art should be achieved. Therefore, technical management on it should be strengthened and special art structure analysis made in an effort to ensure that the application of its brocade techniques can meet the technical management and application demands in the developing modern society and also the art teaching management demands. After analysis and summarization, the national characteristics and art composition of Tujia brocade art are mainly summarized into the following aspects. The national characteristics of Tujia brocade include diversifed forms, bright and vivid colors, ideographic patterns and symmetrical design. The composition of Tujia brocade art is featured with unique art composition, artistic patterns and structures and application of artistic elements and selected connotation of traditional culture.

\section{References}

[1] Xiaoyan Song. Application and Innovation of Tujia Nationality's Brocade Elements of Western Hunan in Modern Clothses[J]. Art Science and Technology, 2016, 29(10): 115117. (in Chinese)

[2] Wanfang Tao. Analysis on Characteristics of Hunan Embroidery, Miao Embroidery and Tujia Brocade and Study on Craftsmanship Inheritance[J]. Modern Women: Theory Edition, 2015, 15 (10): 249-249. (in Chinese)

[3] Si Yang. Enlightenment of Tujia Brocade Art of Western Hunan on Fine Art Design Teaching[J]. Journal of Hunan Industry Polytechnic, 2017, 17(2): 57-59. (in Chinese)

[4] Qianqian Ma. Brief Analysis on the Cultural Connotation and Artistic Characteristics of Tujia Brocade[J]. Literature Life (Next Trimonthly Publication), 2016, 12(2): 1256-1258. (in Chinese)

[5] Xiao Su. Brief Analysis on the Pattern Composition Characteristics of Tujia Brocade of Western Hunan[J]. Art Science and Technology, 2016, 29(4): 75-75. (in Chinese)

[6] Xiao Su. Exploration and Analysis on the Value of Tujia Brocade of Western Hunan[J]. Modern Decoration: Theory, 2015, 25(8): 147-149. (in Chinese)

[7] Yi Li. Innovative Application of Tujia Brocade Patterns and Symbols of Western Hubei in Package Design[J]. Arts Exploration, 2015, 29(2): 114-115. (in Chinese)

[8] Luqi Mo. Reference Study on the Influence of Tujia Nationality Brocade Elements in Modern Design[J]. Art Science and Technology, 2016, 29(10): 1256-1257. (in Chinese) 